IOS Press

\title{
Integrating statistical and geospatial information, cultures and professions: International developments and Australian experience
}

\author{
Gemma Van Halderen ${ }^{\mathrm{a}, *}$, Stuart Minchin ${ }^{\mathrm{b}}$, Martin Brady ${ }^{\mathrm{a}}$ and Greg Scott ${ }^{\mathrm{c}, \mathrm{d}}$ \\ ${ }^{a}$ Australian Bureau of Statistics, Canberra, Australia \\ ${ }^{\mathrm{b}}$ Geoscience Australia, Canberra, Australia \\ ${ }^{\mathrm{c}}$ United Nations Statistics Division, New York, USA \\ ${ }^{\mathrm{d}}$ Department of Infrastructure Engineering, The University of Melbourne, Melbourne, Australia
}

\begin{abstract}
For more than half a century, the United Nations (UN) Statistical Commission has been the highest body of the global statistical system. Bringing together Chief Statisticians, the UN Statistical Commission considers and decides upon statistical standards and the development of concepts and methods, and their implementation at the national and international level. In contrast, the UN Committee of Experts on Global Geospatial Information Management has existed for only the last 5 years. Established by the UN Economic and Social Council (ECOSOC) in 2011, the Committee brings together senior national government geospatial experts to develop strategies to build and strengthen national capacity on geospatial information, as well as disseminate best practices and experiences of national, regional and international bodies on geospatial information.

The $60^{\text {th }}$ International Statistical Institute World Statistics Congress, held in Brazil in July 2015, recognised the importance of the integration of statistical and geospatial information. The then President of the International Association for Official Statistics, Professor Kawasaki, used his Presidential Address to shine a light on this important area for official statistics.

Driven by a growing demand for better data for more informed decision-making, there is an increasing body of material available about the technical aspects and benefits of bringing together statistical and geospatial information, but little has been written about the cultural aspects of two diverse professional communities working together. This paper focuses on some of these cultural aspects, and highlights cooperation underway globally, and nationally within Australia, and provides some suggestions for further improvement.
\end{abstract}

Keywords: Official statisticians, geospatial experts, big data, Earth observations, Sustainable Development Goals, integration of statistical and geospatial information

\section{Introduction}

The UN Statistical Commission, established in 1947, is the highest entity of the global statistical system, bringing together on an annual basis Chief Statisticians

* Corresponding author: Gemma Van Halderen, Locked Bag 10, Belconnen, A.C.T., 2616 Australia, Tel.: +61 26252 6977; E-mail: g.vanhalderen@abs.gov.au. from Member States and related specialised agencies from around the world. As a full UN intergovernmental body, it is the highest decision making mechanism for international statistical activities, especially in the setting of statistical standards and the development of concepts and methods and their implementation at the national and international level.

Originally established due to the need for concerted action to achieve an integrated system in the collection, 
processing and dissemination of international statistics, the UN Statistical Commission assists the UN Economic and Social Council (ECOSOC), as a fully functional Commission, in five areas: promoting the development of national statistics and the improvement of their comparability; coordination of the statistical work of specialised agencies; development of the central statistical services of the Secretariat; advising the organs of the UN on general questions relating to the collection, analysis and dissemination of statistical information; and promoting the improvement of statistics and statistical methods generally.

Geospatial experts from Member States of the UN are currently exploring a similar path. In 2009, the UN Statistics Division convened an informal consultative meeting with geospatial information experts from different regions of the world. The experts discussed how to better coordinate various regional and global activities on geospatial information and related management issues. Subsequent to the consultative meeting, the UN Statistics Division, jointly with the UN Cartographic Section, convened three preparatory meetings on global geospatial information management: the first in Bangkok in October 2009; the second in New York, in May 2010; and the third one also in New York, in April 2011

In October 2009 and February 2010 respectively, the 18th UN Regional Cartographic Conference for Asia and the Pacific and the 41st session of the UN Statistical Commission both discussed the issue of global geospatial information management. The UN Statistics Division Secretariat was requested to initiate discussion with Member States and relevant stakeholders, and prepare a report for the approval of ECOSOC on global coordination of geospatial information management, including consideration of the possible creation of a UN Global Forum on Geospatial Information Management. In July 2010, ECOSOC requested the UN Secretary-General to submit to ECOSOC at its 2011 substantive session a report on global geospatial information management [10]. This decision paved the way for subsequent global geospatial information management preparatory activities.

Taking into account the urgent need to take concrete action to strengthen international cooperation in the area of global geospatial information, at its substantive session in July 2011, ECOSOC considered the report of the Secretary General [12] and adopted a resolution to create the UN Committee of Experts on Global Geospatial Information Management (UNGGIM) [11]. The first session of the UN Committee of
Experts was held in October the same year in Seoul, Republic of Korea, in conjunction with the First High Level Forum on Global Geospatial Information Management. This was the first time that geospatial experts from 90 countries met in the context of a UN initiative to enhance global cooperation in the field of geospatial information management.

This paper presents an account of the journey of the two communities, the official statisticians and the geospatial experts, as they come together to meet their respective mandates under the UN Statistical Commission and UN Committee of Experts on Global Geospatial Information Management. The paper uses the experiences from the two professional communities based in Australia to highlight changing practices and lessons learnt, and is structured as follows.

We first discuss coordination activities of statistical and geospatial agencies, including the lead role that Australia's National Statistical Organisation and Geospatial Organisation have played in international and domestic developments. Section three discusses the development of national statistics, including geospatial statistics, and the improvement of their comparability. Section four discusses advice that the statistical and geospatial communities have provided to organs of the UN on the 2030 Agenda for Sustainable Development. Section five discusses the promotion of improvements to statistics and statistics methods generally. The paper concludes with a general discussion on key lessons learnt and suggestions for ongoing improvement.

\section{Coordinating the statistical and geospatial work of specialised agencies}

\subsection{Australian Bureau of Statistics - Australia's central statistical authority}

The Australian Bureau of Statistics (ABS) is Australia's central statistical authority. The ABS is internationally recognised as a world leader in official statistics, unleashing the power of demographic, economic, social and environmental statistics for a better Australia.

In 2012, the ABS led, on behalf of the global statistical system, a review of national geospatial activities within Member States with a focus on the linking of socio-economic information to a location. The review was based on a global consultation of user needs and challenges, areas where the value and usability of of- 
ficial statistics could be enhanced through the application of a location context, and raised awareness of national geospatial activities and how national statistical offices could play a role in linking social-economic and spatial information [18].

Fifty-two countries contributed to the review, a remarkable response to annual UN Statistical Commission programme review processes. In discussing the findings of the review, the UN Statistical Commission recognised the importance of the integration of geospatial information and statistics in supporting social, economic and environmental policy decision-making, including at the sub-national level. It strongly supported the linking of social, economic and environmental data to time and location attributes in order to enrich and maximise the potential of statistical information, while noting the need to provide technical assistance to countries, developing countries in particular, in the early stages of the integration process.

The UN Statistical Commission endorsed three concrete proposals drawn from the recommendations of the review: a proposal to organise an international conference as a way of reaching out and developing best practices, bringing together both statistical and geospatial professional communities; a proposal to establish an expert group composed of representatives of both statistical and geospatial communities to carry out work on developing a statistical-spatial framework as a global standard for the integration of statistical and geospatial information, addressing various technical issues (for example, the choice of basic units), as well as institutional and information policy issues, especially those related to confidentiality; and a proposal to develop an international statistical geospatial framework, taking into account existing national and international efforts.

In terms of culture, a few observations can be made about the review. The review itself was led by a geospatial expert engaged by the ABS. This expert was wellrespected within the Australian geospatial community and could provide the appropriate leadership and guidance to the review. The expert collaborated with official statisticians, thus helping to bridge terminology differences, the analysis of different user expectations and needs, and influence directions of the review.

To achieve the objective of integrating statistical and geospatial information, endorsement of these three concrete proposals by the official statistical community was necessary but not sufficient. At the third session of the UN Committee of Experts on Global Geospatial Information Management, held in July 2013, the importance of integrating geospatial information with statistics was also acknowledged. The UN Statistical Commission's decision to establish an Expert Group was also endorsed by the UN Committee of Experts, as was its mandate to develop a statistical geospatial framework as a global standard for the integration of statistical and geospatial information.

An important cultural aspect for reaching this joint endorsement was a presentation to the UN Committee of Experts on Global Geospatial Information Management outlining the findings of the UN Statistical Commission review and its recommendations. This presentation, to geospatial experts, was given by an official statistician. This was an important professional as well as symbolic approach. The presentation led to more than twenty supportive interventions from geospatial experts in support of the review's findings and recommendations: a significantly important signal and outcome.

\subsubsection{International workshops}

As proposed by the review of national geospatial activities discussed earlier and endorsed by the UN Statistical Commission, an international conference, or Global Forum on the Integration of Statistical and Geospatial Information was convened on the margins of the fourth session of the UN Committee of Experts on Global Geospatial Information Management in August 2014 [16]. The Global Forum brought together more than 200 senior leaders from 73 countries to discuss the strategic vision and goals for the integration of statistical and geospatial information - a world first. Organisers and participants at the Global Forum all agreed that it had met its objective to reach out and develop best practices by bringing together statistical and geospatial professional communities.

In terms of culture, the Global Forum was purposely held on the margins of the fourth session of the UN Committee of Experts on Global Geospatial Information Management. In other words, a decision was made to have senior leaders from the official statistical community join senior leaders from the geospatial community at their meeting. This enabled maximum coverage of geospatial experts to the Global Forum event.

In addition to the global statistical community agreement to hold an international workshop, the geospatial community also decided that an international workshop would be a means to initiate a dialogue and to ensure inclusive global consultations and communications with relevant experts in determining the metrics of a statistical-geospatial framework. An International 
Workshop on Integrating Geospatial and Statistical Information was convened by the UN Statistics Division in Beijing, China in June 2014 [17]. Hosted by the National Administration of Surveying, Mapping and Geoinformation of China (NASG), the workshop was initially intended to be quite small, less than 50 participants, technically orientated, and to provide a means to 'gauge' how the two professional communities might engage with the statistical geospatial framework concept, and with each other.

Following strong interest and expansion of capacity, the International Workshop brought together a blend of 147 geospatial and statistical technical experts from 41 countries that came prepared for an engaging and productive meeting. With 8 keynote and 29 technical presentations from 28 country experts, the three day meeting discussed and demonstrated the importance of geography and geospatial information to population census activities, and for collecting, processing, storing, integrating, aggregating, and disseminating data on appropriate platforms. The Workshop also provided the opportunity for participants to share country experiences of the benefits that national geospatial information authorities have derived from meeting the specific needs of census geography/cartography and statistical analysis, and their overall cooperation with national statistical offices.

In terms of culture, the level of participation and breadth of technical content covered from across all geographic regions, developed and developing countries, was quite surprising. As a key outcome message, participants understood the importance of the journey to unite our professions and business, and the collaboration and cooperation that is required to achieve this commitment. With the context that our governments and end users want relevant information and knowledge, it is up to us to transform our substantial data resources and intellect into an overall information management framework through institutional integration.

\subsubsection{Expert Group}

As agreed by both the UN Statistical Commission and the UN Committee of Experts on Global Geospatial Information Management, an Expert Group on the Integration of Statistical and Geospatial Information was formed in 2013. The Expert Group initially comprised approximately 20 member states of the $\mathrm{UN}$, with an equal balance of official statisticians and geospatial experts. However, since its first meeting, it has grown to comprise 35 members from 26 countries and 4 organisations. From the 26 countries represented,
21 have membership through official statistical agencies and 12 through geospatial experts. Interestingly, and positively, a small number of countries have nominated national representatives from both their statistical and geospatial agencies to be on the Expert Group. Figure 1 shows the diversity of countries represented on the Expert Group and their professional expertise.

The Expert Group has formally met twice since its inception. At the first meeting in October 2013, held in New York, USA, the Expert Group discussed and agreed on a Terms of Reference that explicitly asked the Group to evaluate the statistical geospatial framework developed by the ABS and determine if and how it could be internationalised. The Terms of Reference were subsequently endorsed by both the UN Statistical Commission and the UN Committee of Experts on Global Geospatial Information Management.

At the second meeting of the Expert Group, held in May 2015 in Lisbon, Portugal, the Expert Group evaluated the statistical geospatial framework developed by the ABS and agreed it is a high-level framework that permits the application of the framework principles to the local circumstance of individual countries. The Expert Group discussed and agreed that the practical application of the principles in countries such as Mexico provide a powerful demonstration of the benefits of these principles, and that the Generic Statistical Business Process Model (GSBPM), developed by the UN Economic Commission for Europe Conference of Statisticians and assessed through a geospatial lens by the European Geography and Statistics Forum for Eurostat, provides a link to internationally agreed statistical processes for geospatial information.

The Expert Group agreed to prepare a Global Statistical Geospatial Framework incorporating aspects of the three models - the Australian model, the practical application of the model in UN member states such as Mexico, and the GSBPM - as the basis for a Global Framework.

The third meeting of the Expert Group was recently held in April 2016 in Paris on the margins of the Conference of European Statisticians. The Expert Group provided final comments on an advanced draft of a proposal for a Global Statistical Geospatial Framework. The expert group agreed that this proposal would be moved to the global consultation phase. The Global Framework would then be submitted to the the UN Committee of Experts on Global Geospatial Information Management in 2016 and the UN Statistical Commission early 2017 for adoption. It also sought to clarify future plans for the consolidation of material that 


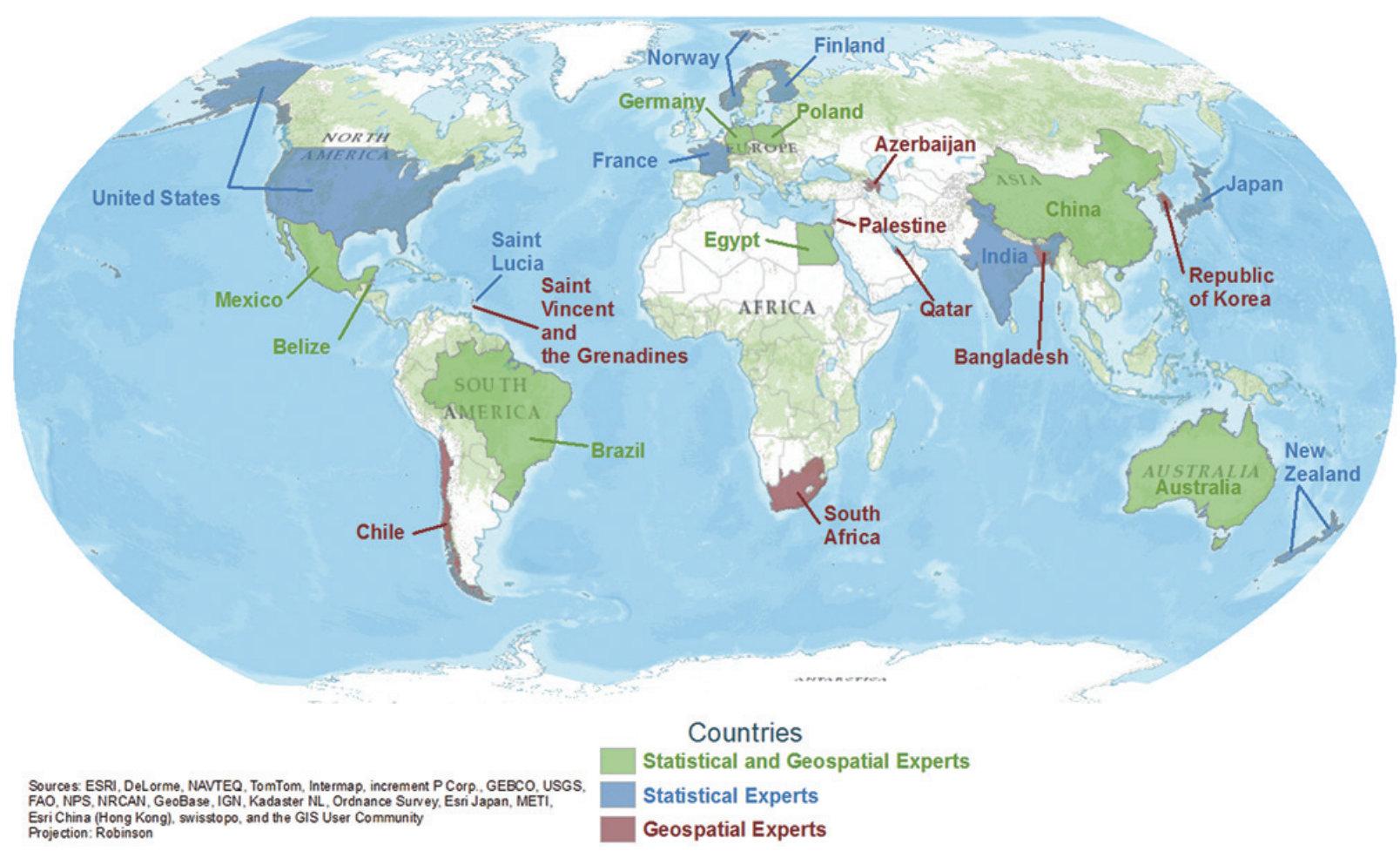

Fig. 1. 2015 membership of the Expert Group on the integration of statistical and geospatial information.

would support the framework and promote and support its implementation in global initiatives such as the global indicator framework for the Sustainable Development Goals (SDGs) and the UN 2020 Round of Population Censuses. ${ }^{1}$

The Expert Group could not have achieved such progress with its mandate without the interdisciplinary nature of the Expert Group membership or the strong support from their governing bodies - the UN Statistical Commission and the UN Committee of Experts on Global Geospatial Information Management. The Expert Group is co-chaired by Australia and Mexico, representing the official statistical community (Australia) and the geospatial science community (Mexico). Participants from inter-governmental groups, such as the European Commission, also attend and several members are also members of professional organisations such as the International Association of Official Statisticians, the International Statistics Institute and the European Forum for Geography and Statistics.

\subsubsection{Global statistical geospatial framework}

It is now readily accepted that integrating statistical and geospatial information is critical for: regional,

\footnotetext{
${ }^{1}$ http://ggim.un.org/UN_GGIM_Expert\%20Group.html.
}

national and global decision making processes; measuring and monitoring sustainable development goals; supporting data sharing between institutions; promoting investment and capability building in geospatial and statistical information; building institutional collaboration between geospatial and statistical communities; and for unlocking new insights that would never have been possible by looking at socio-economic or geospatial data in isolation. The challenge is "how best to achieve this integration in an effective and consistent way" [18]. The Global Forum on the Integration of Statistical and Geospatial Information, mentioned earlier, identified that "there is an urgent need for a mechanism, such as a global statistical-spatial framework, to facilitate consistent production and integration approaches for geo-statistical information" [16].

The ABS recognised some time ago the need for and challenge of better integration of geospatial and statistical information and responded by developing the Statistical Spatial Framework [6]. This framework provides Australia with a common approach to connecting socio-economic or people-centric information to a physical location, and improves the accessibility and usability of geospatially-enabled information.

The Statistical Spatial Framework consists of five principles that are considered essential for integrat- 
ing geospatial and socio-economic information. These are: authoritative geospatial infrastructure and geocoding; data management; common geography; statistical and geospatial metadata interoperability; and accessible and useable geostatistics. Attachment 1 details the vision, goals and outcomes of these principles, as well as the Australian implementation of these generic principles.

As discussed earlier, the Expert Group has debated the Australian Statistical Spatial Framework at both of its meetings and heard from several countries applying the framework to their national circumstances. The Expert Group has concluded that the Australian Statistical Spatial Framework is a practical, principle-based framework that is flexible enough to be customised to suit national contexts. Moreover, the framework is an effective mechanism to improve the geospatial enablement of statistical information so that it can be effectively integrated with data from national and international geospatial and statistical information infrastructures to support analysis and informed decisionmaking. The framework is also recognised as a tool for encouraging thinking and discussion between geospatial and statistical communities, especially as institutions modernise and transform their infrastructure and technology.

The Statistical Spatial Framework and its global parent, the Global Statistical Geospatial Framework, provide a bridge between the official statistical and geospatial profession. Statistical units are geocoded using a geospatial, addressing layer. Data is then released for the geographic boundaries in the boundary layer. This supports integration of data across diverse sources and provides the bridge between statistical datasets through use of a common geography. As more data is released on a common geography, it creates an increasingly valuable network of integrated information.

For developing countries, the Global Statistical Geospatial Framework has been designed to be flexible enough to accommodate differing levels of statistical and geospatial infrastructure capability. For example, not all countries have standardised addressing systems or methods to accurately geocode location descriptions. This flexibility in the Global Framework was incorporated as a result of input provided through the geospatial and statistical members of the Expert Group. That said, the Global Framework also provides a road map for developing countries to guide development of both their statistical and geospatial infrastructure, with a focus view to fully implement the prin- ciples and realise the benefits offered by the Global Framework. The Expert Group also provides a rich source of information and advice for those countries wishing to learn, and improve on, the experiences of other countries that have been working on these infrastructure elements for some time.

Culturally, the development of the Australian Statistical Spatial Framework would not have been possible without the expertise and experience of a geospatial expert engaged by the ABS to undertake this work. Collaborating with official statisticians, the geospatial expert was able to identify principles and linkages to existing Australian and international standards, both statistical and geospatial, which could be used in the application of the principles. For the elevation of the Statistical Spatial Framework into a Global Statistical Geospatial Framework, strong global collaboration between the official statistical and official geospatial communities was essential. The Expert Group members, and the application of the Statistical Spatial Framework to their national circumstances, demonstrated its applicability. A key cultural consideration was the ability of the two professions to agree on principles, enabling the implementation of those principles to be guided by national circumstances.

\subsection{Geoscience Australia - Australia's official geoscience agency}

Geoscience Australia is Australia's official geoscience agency (modern equivalent to national mapping agency). Geoscience Australia applies geoscience to Australia's most important challenges by providing geoscience information, services and capability to the Australian Government, industry and stakeholders.

In 2009, a geospatial expert from Geoscience Australia was Chair of the UN Permanent Committee on GIS Infrastructure for Asia-Pacific and the UN Regional Cartographic Conference for Asia-Pacific, and was directly involved in the journey of Member States described earlier - the informal consultative meeting in 2009, the three preparatory meetings held during 2009 and 2010, the resolution to ECOSOC to bring together geospatial experts through a Global Geospatial Information Management initiative, and the inaugural meeting of the new UN Committee of Experts on Global Geospatial Information Management. With this experience and background, the geospatial expert took up a role in the UN Statistics Division in March 2012 to coordinate the subsequent meetings and technical substantive agenda of the UN Committee of Experts. Un- 
der the leadership of the then Director of the UN Statistics Division, Professor Paul Cheung, the geospatial expert from Geoscience Australia ensured the Global Geospatial Information Management initiative made significant strides.

From the outset, Geoscience Australia has recognised the importance of global attention to important geoscience challenges. Geoscience Australia lead Australia's delegation to the UN Committee of Experts on Global Geospatial Information Management, and has been active and influential participants at Committee meetings. Geoscience Australia have, in particular, recognised the benefits and need for a global geodetic reference system, and the role that a UN mandate can play in achieving this. They have co-chaired a Global Geodetic Reference Frame Working Group which, in February 2015, achieved the first ever geospatial resolution by the UN General Assembly - that of a Global Geodetic Reference Frame for Sustainable Development [14]. The resolution calls for greater multilateral cooperation on geodesy, including the open sharing of geospatial data, further capacity-building in developing countries and the creation of international standards and conventions.

Like the official statistical community, Geoscience Australia recognises the importance of standards for the comparability and coherence of information, as well as for efficiency and maximising technological integration. However, in comparison to the official statistical community, geoscience and geospatial standards are developed and endorsed not by the UN but by groups such as: Technical Committee 211 of the International Organization for Standardization (ISO/TC211); the Open Geospatial Consortium (OGC), an international voluntary consensus standards organisation; the International Hydrographic Organization (IHO); and the Intergovernmental Group on Earth Observations (GEO). Geoscience Australia subscribe to and participate in these groups on behalf of Australia.

The importance of standards and information models has been identified by the Expert Group as critical to ensuring the interoperability of statistical and geospatial information, both to enhance integration of data for analysis and to facilitate machine to machine access and processing of these two types of data. Collaboration between the Geospatial standards organisations and the statistical organisations involved in the statistical community's statistical modernisation project will be critical to ensuring this interoperability. It will also be vital to ensure the integration of geospatial capabilities in statistical business processes.
Geoscience Australia has been very supportive of the ABS' efforts to progress the integration of statistical and geospatial information. ABS join Geoscience Australia as part of Australia's delegation to the UN Committee of Experts on Global Geospatial Information Management. Of the ten issues under consideration by the UN Committee of Experts, the ABS leads Australia's contribution to the topic on the integration of statistical and geospatial information.

\section{Developing national statistics including geospatial statistics, and the improvement of their comparability}

The development of national statistics, and the improvement of their comparability, is one of the five roles of the UN Statistical Commission aimed at achieving an integrated system in the collection, processing and dissemination of international statistics. The ABS recognised some time ago the need for and challenge of better national geospatial statistics, and has responded in a number of ways. In this section, we discuss two recent improvements to Australia's official statistics: grid-based statistics and Land Accounts.

\subsection{Grid-based official statistics}

Official statisticians collect, compile, analyse and disseminate statistics. Our dissemination techniques are diverse - from tables, through to media releases, twitter feeds, infographics, public-use files and choropleth maps.

Statistics disseminated through choropleth maps are, more often than not, based on geographic regions developed and used by official statisticians. These geographic regions often have their genesis in population censuses where the primary purpose of these regions is to support production and release of robust and high quality official population estimates. Alternatively, these regions are derived from administrative geographies developed for local government and administration purposes. The original purpose of these regionalised population estimates are often to manage electoral processes, such as determining electoral districts, and the distribution of taxes to state and provincial governments. These geographic regions are now also used to disseminate official statistics and data, across a wide range of socio-economic topics. They are also used for information discovery applications that allow users to navigate to and access data for their re- 
gion of interest. Australia's Data by Region [2] tool enables data to be discovered and accessed for geographic regions of interest chosen by the user.

In contrast, the geospatial community not only makes use of traditional vector data - points, lines and polygons, but also make use of large and often complex grids (known as raster grids) to disseminate most of their earth science data, particularly environmental data. Such data, ranging from local to global in coverage and scale, is captured by remote sensed or Earth observations techniques, and is very large in volume, area and resolution. These grids are typically based on a square array, such as a 1 kilometre by 1 kilometre grid, or a 25 metre by 25 metre grid. Primarily, but not exclusively, acquired by satellites orbiting the Earth at various heights and repeat rates, the main purpose of these grids is to provide and monitor observations of the same piece of Earth over time. The position of the square array does not change - only what is observed within it, and when.

A very powerful way of demonstrating the integration of statistical and geospatial information is to compile, analyse and disseminate statistical information using the same dissemination unit as the geospatial community - grids. European and Nordic countries have been disseminating official statistics using grids for many years, particularly for the purpose of measuring and monitoring local or regional conditions such as population density, commuting, urban sprawl, land use, flood impacts and other related statistics. However, it was not until the end of 2014 that Australia first produced official statistics based on a grid and it is worth noting, this came about due to a specific cultural environment within the ABS.

Since the early 1990s, the ABS has built and fostered a strong geospatial team who have developed strong relationships with statistical teams within the organisation. This has built an environment within the ABS that is capable of combining statistical data and concepts with associated geospatial concepts. The Australian Population Grid [1] evolved in this environment and was developed and delivered by a team of ABS geospatial experts. The team had to overcome technical and cultural barriers to deliver the final product. Typical statistical issues, including confidentiality, had to be addressed by encouraging official statisticians to look at these issues through a 'how can it be done' lens. Statistical weighting methods were also applied in concert with geospatial data to distribute population data to the grid. Working with dissemination tools designed for statistical standards rather than geospatial standards also required some creativity and new dissemination approaches.

The Australian Population Grid incorporates population data from the 2011 Australian Census of Population and Housing modelled to standard $1 \mathrm{~km}^{2}$ grid cells across Australia. This data has been modelled from confidentialised data for small geographic units, known as Mesh Blocks. Within each populated mesh block, all known or likely residential dwellings were identified using existing, geospatially enabled administrative data sources. The vast majority (over 99.9\%) of the points used to model the population grid were sourced from the Australian Geocoded National Address File (GNAF). The data was then distributed equally across these points and aggregated to the grid cells.

The knowledge of the geospatial experts working on this project within the ABS was founded in a combination of experiences - multi-disciplinary academic training, on the job work experience in both population and environmental statistics, and for some individuals, an earlier career with Geoscience Australia.

\subsection{Land accounts}

Since 1993 the UN Statistical Commission has played a significant role in elevating the System of Environmental-Economic Accounting (SEEA) to its status as an international statistical standard. Within the SEEA there are many types of accounts, including water accounts, energy accounts and land accounts. Work continues on the development of standards for biodiversity and ecosystem accounts.

Land accounts are a tool for integrating information about land and disseminating it in a statistical accounting format. Information about land is inherently of a geospatial nature, therefore land accounts are an excellent example of the integration of statistical and geospatial concepts. Land accounts integrate and display information for a specific region or regions of interest, and track changes for land attributes including use, cover and value over time. Land parcels are often chosen as the minimum geospatial building block for land accounts because they are a commonly available source of administrative information relating to land. Earth observations, including satellite imagery, are also key sources of information about land and the ABS has worked closely with Geoscience Australia to access remotely sensed land cover data for all of its land accounts.

Australia first produced a trial land account for the catchments of the Great Barrier Reef in 2011 [3]. 
This land account was developed with the support of the Queensland Government to demonstrate the concept of land accounting and the power of statistical data to inform policy decisions. The assistance of the Queensland Government in making their administrative database of land valuations available to the ABS was crucial to the success of the land account. Information from the Land Account was used to inform debate and decision-making on a wide range of issues, including population settlement; land management; measuring the health of the environment; emergency management and the sustainable production of goods and services. The trial was a success and the ABS has extended its production of land accounts to the States of Victoria (2012) [7], Queensland (2013) [4] and South Australia (2015) [5].

The ABS Land Account is designed to be an interactive publication and is best viewed online. Each land account has introduced a new feature to support its dissemination. Two examples are $\mathrm{kml}$ files for use in Google Earth, which enable users to interact with the data geospatially, and the publication of grids of land value to enable further geospatial research into land based issues and policy.

ABS is actively considering how to further extend the use of geospatial and Earth observation data to facilitate other environmental accounts; particularly through ecosystem accounts and water accounts. In addition, active consideration is being given to how information from environmental accounts might integrate with other information on land use and management from the ABS Agriculture Census and other agricultural collections

\subsection{Improving comparability}

The production and dissemination of official statistics for grids and in land accounts are important steps towards integrating statistical and geospatial information, but they focus on dissemination as the integration point. Can integration be achieved earlier in the statistical production cycle?

The ABS and Geoscience Australia have commenced a collaborative effort to bring together traditional statistical data sources, specifically survey data, with traditional geospatial data sources, specifically Earth observations data.

Geoscience Australia are leading a small consortium, including CSIRO and the National Computational Infrastructure in the development of a new technology called the Australian Geoscience Data
Cube [8]. The Data Cube is significantly lowering the technical barriers to using Earth observation data, not just within Australia but also internationally. The ABS has been trailing the use of the Earth observation data for estimating crop yields since 2014 [9] and has commenced trailing the use of the Earth observation data directly for official statistical purposes, such as environmental statistics - noting the ability for Earth observation and geospatial data to monitor the environment at high temporal and spatial resolutions.

Earth observation data within the Australian Data Cube is compatible with the emerging Discrete Global Grid System standard under development within the Open Geospatial Consortium. This Grid System could also be used to manage and integrate other data sources, not just Earth observation data. Geocoding traditional statistical data sources such as census, survey and administrative data, to an implementation of the Discrete Global Grid System is an option for addressing the technical challenges of integrating statistical and geospatial data in a flexible and integrated way.

There have been several trials by ABS of using the Earth observation data in the Australian Geoscience Data Cube. The first trial, commenced around 2014, was led by official statisticians applying their expertise, methodological tools, and experiences to the Earth observations data as a new, big data source for official statistics. Specifically, acquiring the data held within the Data Cube and then applying traditional surveybased expertise and methods to a non-traditional survey based data source (i.e. Earth observation data) [9]. Further work to directly utilise these methods and Earth observation data in conjunction with unit record data from the ABS Agricultural Census is anticipated to provide substantial enhancement to the frequency and range of data on agricultural land use and production in the future.

A second trial has recently commenced taking a different path; that of ABS statistical and geospatial experts directly collaborating with Geoscience Australia geospatial experts to apply their combined knowledge, tools and experiences to the Earth observations data in much the same way that they used their expertise to compile, analyse and disseminate grid-based official statistics. This project will explore use of the information in the Geoscience Data Cube using the National Computational Infrastructure to provide information on land cover and soil exposure at a national level. The primary aim of the project is for ABS geospatial experts, working with the more traditional official statisticians, to bridge the methodological gap between the 
two professions. This approach proved successful in the case of both the Population Grid and the Land Accounts, and we are hoping to replicate it with the new data source, Earth observations, through this trial.

\section{Advice to organs of the United Nations}

One of the five roles of the UN Statistical Commission aimed at achieving an integrated system in the collection, processing and dissemination of international statistics is to provide advice to organs of the United Nations.

In September 2015, the UN General Assembly adopted a new and ambitious development agenda known as Transforming our World: The 2030 Agenda for Sustainable Development [15]. The 2030 Agenda is the global policy to guide the way we collectively manage and transform the social, economic and environmental dimensions of humanity and our planet over the next 15 years. It will be anchored by 17 Sustainable Development Goals (SDGs), 169 targets and a global indicator framework, in order to measure and monitor progress. In this regard, the indicators will need to have global integrity, be accessible and timely, and enable reliable disaggregation to help with the measurement of progress and ensure no one is left behind.

The 2030 Agenda calls for data and information from existing reporting mechanisms to be used where possible. It also commits to develop broader measures of progress to complement gross domestic product.

A commitment to the development of broader measures of progress was originally made at the Rio+20 summit, held in Brazil in 2012, twenty years after the first Earth Summit. The outcome document from this summit, The Future We Want [13] recognised the need for broader measures of progress to complement gross domestic product in order to better inform policy decisions. The UN Statistical Commission, in consultation with relevant United Nations system entities and other relevant organisations, was requested to launch a programme of work in this area, building on existing initiatives.

A Friends of the Chair group on Broader Measures of Progress was established that, among other things, was asked "to closely monitor the ongoing debate on development frameworks and to keep the Bureau of the Statistical Commission informed ... in order to ensure that a robust statistical measurement approach is incorporated from the outset in preparations for the post-2015 development agenda" [13]. The Friends of the Chair group closely monitored the ongoing discussions and debates of the post-2015 Development Agenda throughout the period leading up to the 2030 Agenda and endorsement of seventeen Sustainable Development Goals and 169 targets.

During this period, the Friends of the Chair group evolved into an Inter-agency and Expert Group on SDG Indicators (IAEG-SDGs), composed of UN Member States and including regional and international agencies as observers. The IAEG-SDGs were tasked, in the 2030 Agenda [15], with providing a proposal for a global indicator framework, and associated global and universal indicators, for consideration by the UN Statistical Commission at its forty-seventh session in March 2016. It is expected that the UN Statistical Commission proposal will be subsequently endorsed by ECOSOC and the UN General Assembly.

The 2030 Agenda specifically demands the need for new data acquisition and integration approaches to improve the availability, quality, timeliness and disaggregation of data to support the implementation of the new development agenda at all levels - including to "exploit the contribution to be made by a wide range of data, including earth observations and geospatial information, while ensuring national ownership in supporting and tracking progress.” [15]. This need has a goal, target and date associated with it, as described in Goal 17 in data, monitoring and accountability: "By 2020, enhance capacity-building support to developing countries, including for least developed countries and small island developing States, to increase significantly the availability of high-quality, timely and reliable data disaggregated by income, gender, age, race, ethnicity, migratory status, disability, geographic location and other characteristics relevant in national contexts." [15].

Whilst the UN Statistical Commission was tasked with developing a global indicator framework, within Australia it was recognised that the Sustainable Development Goals span all three dimensions of the sustainable development agenda: economic, social and environmental, and that the indicator framework required ownership from across the entire Australian Government and its agencies. The ABS therefore collaborated with the Australian Government Department of Foreign Affairs and Trade to bring together Australian Government agencies to seek collaborative input into the proposed indicator framework.

Geoscience Australia contributed extensively to the ABS response to the proposed indicator framework. Geoscience Australia noted the contribution that can be 
made by a wide range of data, in particular Earth observation and geospatial information. These data sources could not only contribute to individual targets, such as water management and deforestation, but also more broadly to a global indicator framework that calls for data and information from existing reporting mechanisms to be used where possible, and for disaggregation by geographic location, amongst other things.

Culturally, ABS was committed to collaboration with its partners in the wider Australian statistical system. Relationships that existed across the Australian Government were called upon, often at short notice, to contribute to the proposed global indicator framework. The ABS had to be open to new ideas and perspectives from across the national statistical system, including the use of new data sources and innovations such as the use of Earth observations data for official statistics.

ABS believes these collaborative and multi-disciplinary approaches must be adopted by other national statistical offices as they modernise and transform if they wish to use new data sources in the production of official statistics, especially with regard to the opportunities provided by geospatial and Earth observation data sources. Culturally, NSOs will need to look beyond traditional statistical methodologies to the methods and technologies used in other disciplines, such as those used in the geospatial community, to make the most of these new data sources. This approach will also require some investment, or collaborative use of resources, in new technologies and methods. This will pose challenges for national statistical offices that have limited or constrained budgets: regional collaboration has been seen as a possible solution to some of these problems.

\section{Promoting improvements to statistics and statistics methods generally}

A key role of the UN Statistical Commission is to promote improvements to statistics and statistical methods generally. Improving official statistics by integrating statistical and geospatial information is one of its current promotional activities. Coupled with this promotional effort, and as noted earlier, is the need to ensure statistical methods are relevant and accessible from the perspective of geospatial information. Confidentiality is one of the statistical methods that vexes the minds of many national statistical organisations as they integrate statistical and geospatial information.

Confidentiality methods are widely known and applied to traditional statistical offerings, such as tables and public use files. Many of these tables and publicuse files will have geographic regions as dimensions; such as statistics for a state or province, or a town or council area. These geographic regions are often designed with population in mind, such as a minimum of 20 persons per square kilometre. Where these geographic regions are used, confidentiality rules, such as a minimum of five persons per output cell, are relatively easy to apply and embed in technological offerings, such as table generating software. When the output cell is a geographic region designed around a non-population based criteria (e.g. a ground water region or a riparian zone, or a 25 by 25 metre grid) more elaborate methods of managing confidentiality must be applied, such as perturbation.

Several countries are tackling this challenge including Australia, Italy, USA and the UK. In time, the experiences and expertise of these countries will be drawn upon by the Expert Group on the Integration of Statistical and Geospatial Information through a dedicated stream of work that will propose a set of guidelines for countries to adopt. A key focus of countries and the Expert Group will be to ensure that the confidentiality methods can be as automated as possible. Manual checking methods, which are both costly and time consuming, are to be avoided or minimised as much as possible.

Data standards is a key area where more work is required and some work in this area is already underway. The cultural issue here is as much about professional paradigms as it is about standards. As noted earlier, the official statistical community has over fifty years of governance by the peak, international statistical standards body, the UN Statistical Commission. Within the geospatial community the private sector has led the application of many new approaches (i.e. google maps, ESRI, Digital Globe). Therefore, the engagement of geospatial standards bodies, such as the ISO and OGC, that encompass both private and public sector, is critical in ensuring globally applicable standards. The Expert Group on the Integration of Statistical and Geospatial Information is confronting this cultural difference as it works through its work program, and is putting in place mechanisms to help address these differences, including the Expert Group itself.

Within the statistical community the elements with Common Statistical Production Architecture, being developed by the UNECE High Level Group for Statistical Modernisation, is expected to provide greater consistency through the use and harmonisation of standards. This harmonisation will allow better integration 
between statistical business process, data management, metadata and infrastructure. National organisations, such as the ABS and Statistics Finland, have identified challenges within this architecture from a geospatial perspective. Internationally, the Expert Group has identified that enhancing data interoperability between the statistical and geospatial communities will require effective mechanisms to incorporate geospatial data, and effective links to existing geospatial standards within this architecture and the statistical standards that it incorporates.

By working together, the official statisticians are sharing knowledge and skills with geospatial experts about the importance of confidentiality to the trust and integrity of official statistics, and how our standards and information models work. In return, geospatial experts are sharing their knowledge and skills of approaches and methods to confidentiality that can be applied to geospatial data sources, such as Earth observations, and geospatial dissemination methods, such as grids and surface models. They are also sharing their experience of developing and implementing modern approaches to standards. This is a truly interdisciplinary approach to official statistics.

\section{Key lessons learnt and suggestions for ongoing improvement}

This paper has traversed the journey, so far, of two communities uniting together to integrate statistical and geospatial information to enrich and empower countries to better measure the progress of their societies and economies, to unleash the power of statistics, and to help measure and monitor the Sustainable Development Goals.

Key to this journey has been a willingness and desire to cooperate, and this is now being replicated in other countries, driven in some way by both willingness and need. For example, while the development of the global indicator framework has largely been a statistical data approach, based on the similar history of the Millennium Development Goals (MDGs), the need for 'geographic location' in a new era of data needs is well recognised. The statistical community is beginning to understand more clearly that geospatial information and Earth observations are able to provide new and consistent data sources and methodologies to integrate multiple 'location-based' variables to support and inform official statistics and the indicators for the SDGs. These methods are able to fill data gaps and/or improve the temporal and spatial resolutions of data, by bringing together information from various sources, particularly those related to the environment.

The ABS has recently released a new strategic Engagement Plan based on three engagement principles: nurture, understand and collaborate. These principles target three outcomes: shared benefit through open relationships that recognise others play a significant role in Australia's statistical system; shared vision by committing ABS to understanding the current and future policy landscape, and the pressures, priorities and pain points of stakeholders; and shared solutions by committing ABS to work together with partners in purposeful ways to inform discussions and decisions, and improve Australia's statistical system.

The relationship between Australia's official statisticians and geoscience experts adopt these three principles. The relationship between the ABS and Geoscience Australia is open and nurtured personally and professionally, such as through our joint representation on the UN Committee of Experts on Global Geospatial Information Management. We listen and seek to understand the pressures, priorities and pain points of our two communities and institutions. For instance, the Chief Executive Officer of Geoscience Australia was the guest speaker at an inaugural ABS Transformation Showcase event, sharing Geoscience Australia's experiences with their institutional transformation as ABS embarks on its own institutional transformation. And finally, we are sharing solutions through many collaborative efforts underway, especially those aimed at integrating statistical and geospatial information.

Having the UN Statistics Division as Secretariat for the two highest governing bodies, the UN Statistical Commission and the UN Committee of Experts on Global Geospatial Information Management, augers well for addressing the challenge of standards and the range of other challenges to be overcome in enhancing the integration of statistical and geospatial information.

\section{Acknowledgements}

The Authors wish to acknowledge the contributions of many official statisticians and geospatial experts working within the Australian: Bureau of Statistics who have contributed to this paper. The views expressed in this paper are those of the authors and do not necessarily represent those of their institutions. 


\section{References}

[1] Australian Bureau of Statistics, Australian Population Grid, 2011. 2014. ABS Cat. No. 1270.0.55.007.

[2] Australian Bureau of Statistics, Data by Region, http://stat. abs.gov.au/itt/r.jsp?databyregion, 2013. Viewed 15 January 2016.

[3] Australian Bureau of Statistics, Land Account: Great Barrier Reef Region, Experimental Estimates, 2011. 2011. ABS Cat. No. 4609.0.55.001.

[4] Australian Bureau of Statistics, Land Account: Queensland, Experimental Estimates, 2013. 2013. ABS Cat. No. 4609.0. 55.003.

[5] Australian Bureau of Statistics, Land Account: South Australia, Experimental Estimates, 2006-2011. 2015. ABS Cat. No. 4609.4.55.001.

[6] Australian Bureau of Statistics, Statistical Spatial Framework, http://www.nss.gov.au/nss/home.nsf/pages/Statistical\% 20Spatial\%20Framework\%20Homepage. 2013. Last viewed 15 January 2016

[7] Australian Bureau of Statistics, Land Account: Victoria, Experimental Estimates, 2012. 2012. ABS Cat. No. 4609.0.55. 002.

[8] Australian Geoscience Data Cube, http://www.datacube.org. au. 2014. Last viewed 15 January 2016. See also: Lewis, A., Lymburner, L., Purss, M.B.J., Brooke, B., Evans, B., Ip, A., Dekker, A.G., Irons, J.R., Minchin, S., et al., (2015) Rapid, high-resolution detection of environmental change over continental scales from satellite data - the Earth Observation Data Cube. International Journal of Digital Earth. http://dx.doi.org. /10.1080/17538947.2015.1111952. Last viewed 20 January 2016.

[9] S.M. Tam and F. Clarke, Big Data, Official Statistics and Some Initiatives by the Australian Bureau of Statistics. International Statistical Review 83 (2015), 436-448.

[10] United Nations Economic and Social Council, Decision 210/240. Global geographic information Management. http: //www.un.org/en/ecosoc/docs/2010/dec\%202010-240.pdf. 2010. Last viewed 15 January 2016.
[11] United Nations Economic and Social Council, Resolution 2011/24 Committee of Experts on Global Geospatial Information Management, http://www.un.org./en/ecosoc/ docs/2011/res\%202011.24.pdf. 2011. Last viewed 15 January 2016.

[12] United Nations General Assembly, Report of the Secretary General on Global geographic information management, http://www.un.org/ga/search/view_doc.asp?symbol $=\mathrm{E} / 2011 / 89$. 2011. Last viewed 15 January 2016.

[13] United Nations General Assembly. Resolution 66/288. The future we want. $2012 \mathrm{https}$ ///sustainabledevelopment.un.org/ futurewewant.html. 2012. Last viewed 15 January 2016.

[14] United Nations General Assembly, Resolution 69/266. A global geodetic reference frame for sustainable development. http://ggim.un.org/docs/A_RES_69_266_E.pdf. 2015. Last viewed 15 January 2016.

[15] United Nations General Assembly. Resolution 70/1. Transforming our world: the 2030 Agenda for Sustainable Development. https://sustainabledevelopment.un.org/post2015/transf ormingourworld. 2015. Last viewed 15 January 2016.

[16] United Nations Statistics Division, Global Forum on the Integration of Statistical and Geospatial Information http://ggim. un.org/docs/meetings/Global\%20Forum/Summary-Report\% 20of\%20the\%20Global\%20Forum.pdf. 2013. Last viewed 15 January 2016.

[17] United Nations Statistics Division, International Workshop: Integrating Geospatial and Statistical Information http://ggim .un.org/International\%20Workshop.html 2013. Last viewed 15 January 2016.

[18] United Nations Statistics Division, Report of the Australian Bureau of Statistics on developing a statistical-geospatial framework, http://unstats.un.org/unsd/statcom/doc13/2013-2ProgReview-E.pdf. 2013. Last viewed 15 January 2016. 


\section{Attachment A: Statistical spatial framework}

Australia's Statistical Spatial Framework is a framework to enhance decision making by using location in a common way to allow seamless integration of administrative, statistical and geospatial information resources. The following diagram outlines the vision, goals and principles embedded within the framework, and the outcomes it will achieve.

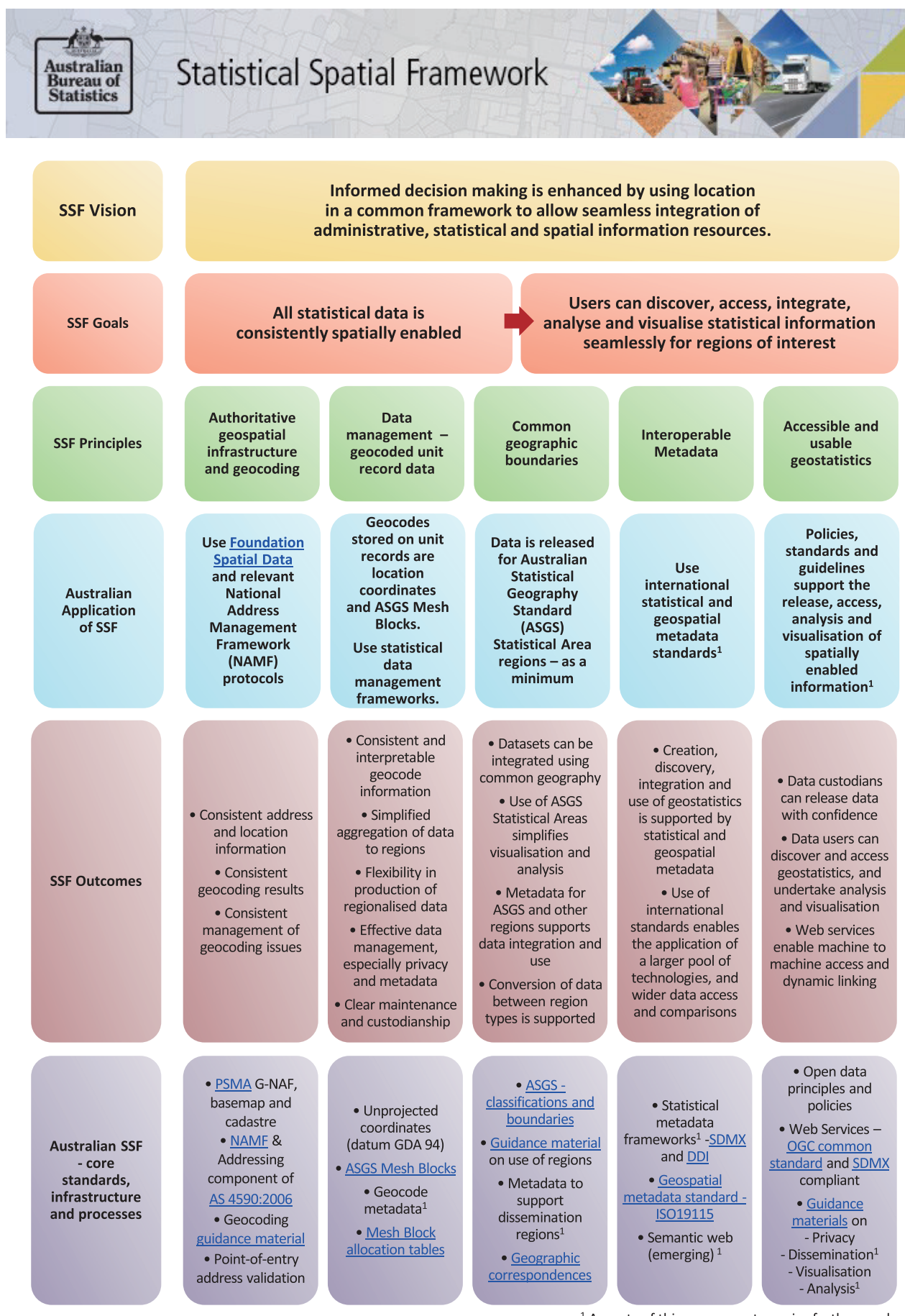

${ }^{1}$ Aspects of this component require further work. 